\title{
Gender and Age Related Differences in Anxiety about Aging
}

\author{
Dr. Rashmi Saxena ${ }^{1 *}$, Prof Archana Shukla ${ }^{2}$
}

\section{ABSTRACT}

Western society has always been somewhat intrigued by anxiety about aging and its causes. In comparison, the study of anxiety about aging has not been given much importance in other cultures. Thus, the purpose of this study was to examine the influence of gender and age on anxiety about aging in a culturally diverse country like India. There were 300 participants ranging in age from 25-35, 45-65 and 65+ who took part in the study. It was hypothesized that a) females as compared to males have greater anxiety about aging, b) In comparison to older respondents younger and middle aged respondents have greater anxiety about aging. A survey method was used in this study and participants were required to complete the Anxiety about aging Scale (AAS). The results supported hypothesis a) and b). Further research and implications are discussed.

Keywords: Anxiety about Aging, Gender, Age

Aging refers to the processes of “accruing maturity with passage of time”. Old age is the closing period in the life span. The goal of geriatrics is not to promote Senescence, but maximize the positive aspects of aging. In the words of the Gerontological Society of America, gerontology should be "adding life to years, not just more years to life".

Aristotle described "old age as a time of disengagement and uncertainty". Plato likewise described "the metamorphosis of the soul with aging to allow for the emergence of the precursors of wisdom and the discovery of new values, meanings not possible to the younger generations". Such philosophically profound statements do not represent the common reality of how aging is actually perceived by people in general. The two words that most often feature in any discourse -whether common or enlightened - about aging are 'fear' and 'anxiety'.

The term "fear" is generally used when the source of the feeling is known. Anxiety, on the other hand, refers to the general apprehension toward an unidentifiable source or uncertain future event

\footnotetext{
${ }^{1}$ Shri Ramswaroop Memorial Group of Professional College, Lucknow, India

${ }^{2}$ University of Lucknow, India

*Responding Author

(C) 2016, R Saxena, A Shukla; licensee IJIP. This is an Open Access Research distributed under the terms of the Creative Commons Attribution License (http://creativecommons.org/licenses/by/2.0), which permits unrestricted use, distribution, and reproduction in any Medium, provided the original work is properly cited.
} 


\section{Gender and Age Related Differences in Anxiety about Aging}

(Byrne \& Kefley 1981; Kalish, 1985). Therefore, one may have a fear of "becoming frail and dependent" or "fear of declining health" (Hooyman \& Kryak, 1993, p. 30, 126), but one can also experience "anxiety about aging" or "anxiety about death." Anxiety about aging can be identified as worry, concern, or nervousness about the ability to care for oneself as well as anticipated decline in health and eventual death. The Ontario Welfare Council (1971, p. 14) describes anxiety about aging as "apprehension, regret, or general negativism toward the aging process and what lies ahead."

India had 90 million elderly persons in 2011 with the number expected to grow to 173 million by 2026 (Dhar, 2012). According to a United Nations Report, India is facing elderly population 'time bomb' which is likely to put additional strain on families and health and welfare services; also elderly women are expected to outnumber men and be left more vulnerable in Indian society (Nelson, 2013). According to population Reference Bureau, the three over arching concerns about India's aging population are health and health care, living arrangements and social support, and income security (Scommegna, 2012). Such statistics combined with frequent reports about old parents being abandoned by their adult children (Faculty and staff assistance offices, July 13th, 2012, "when your children doesn't want you" present a dismal picture that can perhaps be caused by space/finance/time crunch, growing materialism, declining family values, and/or people's negative perceptions about aging and caring for elderly in modern day living even in urban India.

Anxiety about aging has been an area less often researched in India. However, such anxiety should become increasingly important to understand as population ages. The present study was designed to fill such a gap. The main objective of the study was to explore gender and age related differences in anxiety about aging among educated, middle-class adults.

Although gender differences in the effects of anxiety about aging on limited samples in previous studies have provided mixed results, overall the researches find that women experience more anxiety about their own aging than do men (Abramson \& Silverstein, 2006; Cummings, Kroff \& DeWeaver, 2000;). Previous studies have also shown that the older the participants, the more positive they were about personal aging. Interestingly, middle aged and younger respondents are the ones with the largest age-related bias (Motepare \& Lachman, (1989). As Kite and Wagner (2002) argue, this may be because middle-aged adults and younger people see old age as right over the horizon, but still are not quite ready to accept its coming. Due to this they are more anxious toward the aging process and are less likely to accept it gracefully.

Based upon such logic two hypotheses are formulated and tested in the present study. These are: $\mathrm{H}_{1}$ : Women, in comparison to men, experience greater anxiety over aging.

H2: Younger and middle-aged respondents, in comparison to older respondents, have greater anxiety about aging. 


\section{METHOD}

\section{Design}

The sample was divided into six groups by using the two classificatory variables of respondent's sex (male and female) and age ( 25 to 35 years, 45 to 65 years and $65+$ years). All other variables were then examined as dependent variable through $2 \times 3$ ANOVAs to assess if significant variations exist among the groups due to sex and age.

\section{Sample}

A purposive sample of 300 respondents living in Lucknow was used for the present study. Half of these were males, the other half, females. Inclusion criteria consisted of having completed education till at least graduation, not being diagnosed with any illness at the time of the study and belonging to the middle socioeconomic status. The male and the female respondents were further subdivided into four age groups of 25-35 years, 45-65 years, and 65 years and above. In male sample $75 \%$ were graduate, $50 \%$ were post graduate and $25 \%$ were doing some professional courses whereas in female sample $95 \%$ were graduate, $45 \%$ were postgraduate and $10 \%$ were doing some professional courses. All of them were married and employed and their income lies between 10.000 to 30,000 .

\section{Variables and Measures}

Two sets of variables were used in the present study. The first set consisted of the classificatory variables of sex (males vs. females) and age (25-35 years, 45-65 years and 65+ years). These two variables together led to a division of the sample into six subgroups of 'young', 'middle-aged', and 'old' males and females.

The other set of variable consisted of the 'dependent' variable of anxiety about aging. The Anxiety about Aging Scale, AAAS, by Lasher and Faulkender (1993) was used in the present study. AAAS is a 20-items measure that produces a total score based on the answers to 20 questions across the four subscales. The first sub scale is fear of old people consisting of items no. 1, 3, 10, 13 and 19; the second subscale is psychological concern about aging consisting of Items no. 5, 7, 11, 16 and 18; the third sub scale is concern about physical appearance consisting of items no. 4, 9, 12, 15 and 20; and the fourth sub scale is fear of losses consisting of items no. 2, 6, 8, 14, and 17of AAAS. All items on this scale are to be rated on a 5- point scale from "strongly disagree" (scored as 1 ) to "strongly agree" (scored as 5). The theoretical range of scores on the various subscales is from 5 to 25 , with high scores indicating greater anxiety about aging and vice versa.

\section{Procedure}

The questionnaires were constructed consisting of a demographic data sheet besides the 20 items from the AAAS. A Hindi version of AAAS was prepared using the back translation method. Data were collected by administering the questionnaire in face-to-face personal interviews with 


\section{Gender and Age Related Differences in Anxiety about Aging}

the respondents. Initial part of the interview consisted of briefing the participants about the purpose of the study. Participants were requested to fill up a consent form to indicate an understanding that their participation in the study was voluntary and that they can pull out at any time should they wish to do so. Participants were given sufficient time to complete the questionnaires and their questions were answered by the researcher. The questionnaires were collected upon completion and the same were screened to evaluate their usability in the study. Response rate was $72 \%$. Data were analyzed using SPSS version 11

\section{RESULTS}

Table 1 presents Means, SDs and F ratio with respect to the first dimension of Anxiety about Aging - fear of old people. Part B of this table indicates that on this variable, the main effect of age and sex are significant. On fear of old people middle respondents (45-65 years) scored more than younger (25-35 years) and older respondents (65 and above years). Means for females are 11.33 and for males are 8.90, $\mathrm{F}=28.264, \mathrm{p}<.001$. It suggests that females show more fear towards old people than males.

Table 2 present Means, SDs and F ratios with respect to the second dimensions of Anxiety about Aging - a psychological concern about getting old. Part B of this table shows that on this variable main effect of age and sex is significant. On psychological concern younger respondents (25-35 years) scored more than middle (45-65 years) and older (65 and above years) respondents. It indicates that younger respondents show more psychological concern about getting old than do middle and older respondents. Means for females are 14.97 and for males are 13.06, $\mathrm{F}=168.967, \mathrm{p}<.001$. It indicates that females show more psychological concern than males.

The interaction effect of age and sex is also significant $(\mathrm{F}=43.937, \mathrm{p}<.001)$ with respect to psychological concern.

Table 3 presents means, SDs and ratios with respect to the third dimension of Anxiety about Aging - physical appearance. Part B of this table shows that on this variable main effect of age and sex is significant. On physical appearance older respondents (65 and above years) scored more than middle (45-65 years) and younger respondents (25-35 years). It indicates that older respondents are more anxious for their physical appearance than middle and younger respondents. Means for females are 16.23 and for males are 11.77, $\mathrm{F}=168.967, \mathrm{p}<.001$. It suggests that females are more concerned for their physical appearance as compared to males.

The interaction effect of age and sex is also significant $(F=43.937 . p<.001)$ with respect to physical appearance. Remarkable gender differences are seen only among respondents aged 65 and above years. In other two age groups gender differences are small. In 65 and above respondents, females are more anxious toward their physical appearance than males. 


\section{Gender and Age Related Differences in Anxiety about Aging}

Table 4 contains Means, SDs and F-ratio for the fourth dimension of Anxiety about Aging fear of loss. On this variable main effect of age and sex is significant. On fear of loses older respondents (65 and above years) scored more than middle (45-65 years) and younger respondents (25-35 years). It indicates that old respondents have more fear of loosing their dear ones than younger and middle respondents. Means for females 16.45 and for males 14.66, $\mathrm{F}=$ 18.624, $\mathrm{p}<.001$. it indicates that females as compared to males have more fear of losses.

The interaction effect of age and sex is also significant $(\mathrm{F}=39.442, \mathrm{p}<.001)$ with respect to fear of loses. Remarkable gender differences are seen only among respondents aged 25-35 years. In other age groups gender differences are relatively small to be significant. In 25-35 years younger respondents females have more fear of loses than males.

Table 5 contains total scores on the scale of anxiety about aging. On this scale the main effect of sex is found significant. On anxiety about aging females scored more than males (Means58.99 and 48.39, $\mathrm{F}=144.503, \mathrm{p}<.001)$. It indicates that females experience greater anxiety about aging than males.

The interaction effect of age and sex is significant with respect to anxiety about aging. Remarkable gender differences are seen among respondents aged 25-35 years. Among younger respondents females have more anxiety towards their aging process than males.

\section{DISCUSSION}

\section{Gender}

As compared to males females in the present study were found to be more anxious towards their aging process. The 2x3 ANOVA revealed that in comparison to males, females scored higher on overall anxiety about aging (Mean 48.39 and 58.99, $\mathrm{F}=144.503, \mathrm{p}<.01$ ). Thus the first hypothesis which stated that "In comparison to men, women experience their own aging process with a greater degree of anxiety" gets supported by the findings of the present study. "Never ask a woman her age.” This aphorism reflects cultural constructions and assumptions about women's experience with aging. As suggested by the double standard of aging - a term popularized by Sontag(1972) - the loss of status that accompanies aging is more severe for women than men, which leads to the expectation that reminders of aging produce anxiety for many women. This pattern is generally supported by the small literature on aging anxiety.1 Research tends to find that women experience more anxiety about their own aging than do men (Abramson \&Silverstein, 2006; Cummings, Kropf, \& DeWeaver, 2000; Lynch, 2000); however, it should be noted that a few studies-employing smaller, non random samples-fail to find gender differences (Kafer, Rakowski, Lachman, \&Hickey, 1980) or report more concerns among men (Lasher \& Faulkender,1993; Watkins, Coates, \& Ferroni, 1998).Although most research suggests that aging anxiety is greater among women, studies are limited by inadequate attention to the multiple sources of women's concerns about their own aging. Their anxiety may center on any 


\section{Gender and Age Related Differences in Anxiety about Aging}

number of future possibilities, such as health declines, changes in physical appearance, and loss of fertility. Rather than exploring this variation, studies tend to focus on summary indicators of aging anxiety (Cummings et al., 2000; Kafer et al., 1980; Lasher \& Faulkender, 1993). As a consequence, we know little about how multiple sources of aging anxiety are shaped by the various contexts of women's lives. Numerous social factors-race/ethnicity, social class, and family relationships, to name only a few-influence the objective experience of aging, such as the likelihood of having plastic surgery, being widowed, living in poverty, being disabled, or having an informal caregiver. We argue that many of these same factors are likely to influence the subjective experience of aging, including women's concerns about their own aging. We examine the following four clusters of factors and their associations with aging anxiety: women's locations in systems of inequality (e.g., race/ethnicity, social class, and sexual orientation); their connections to social institutions (e.g., marriage, family, and work); the nature of their social ties; and their health status. Many of these factors have not been examined in prior literature, leaving their associations with various sources of women's aging anxiety unexplored. Our purpose is to provide a descriptive analysis of these associations; we do not place greater emphasis on some groups of variables over others. Earlier studies revealed that society stresses the appeal of looking young especially for women. In today' scenario also the commercials on television and advertisements in magazines advertize numerous products on sale for dieting and lotions for younger, whiter looking, wrinkle free skin for females. The fact that in the present study, on physical appearance subscale, significant differences were found between males and females indicates that good physical appearance has become very important for females. Keeping up with social need to stay 'young looking' is now as self absorbing for females as it is for males. Besides, one study had found that young facial features were associated with more positive traits and behaviors than those with older facial features (Hummert, Garstka and Shaner, 1997). As Susan Sontag $(1978,73)$ contends that 'Getting older is less profoundly wounding for a man---. Men are "allowed" to age, without penalty, in several ways that women are not'. There is no doubt that there are heavy pressures on women to 'stay' young and 'look' young, which are less pronounced for men as they age (Featherstone and Hepworth, 2000). In our society where youth is highly valued, people are considered "old" at much younger ages. This emphasis on youth translates into considerable expenditure on makeup, cosmetics, and surgeries to hide signs of aging particularly among women. The cultural devaluation of age may influence the selfperceptions of both men and women. However, it has been argued that the social and psychological consequences of aging are greater for women. In the magazine article that popularized the double standard of aging hypothesis, Sontag (1972) made the case that quality most highly valued in men- competence, autonomy and earnings potential- increase over the middle decades of life, while those most highly valued in women- physical attractiveness and sexual availability to men- decline with age. Women tend to maintain more youthful identities than men of the same chronological age (Pinquart and Sorensen, 2001). Considering this pattern from the point of view of the socially situated self (Goffman, 1959), women may have greater incentives than men to present and maintain youthful appearances enabling them to protect their 


\section{Gender and Age Related Differences in Anxiety about Aging}

valued identities as "young women". Consistent with this claim, signs of aging or perception toward older people are viewed more negatively in women, and women are more likely than men to use age concealment techniques (Harris, 1994). Providing another illustration of the greater devaluation of age in women, both the sexes tend to view the onset of middle and old age as occurring at younger chronological ages among women (Neugarten et al., 1965, Seccombe and Ishii-Kuntz, 1991 and Zepelin et al., 1986-87). In the study by Lynch (2000) which included a total of 516 males and 633 females, women were found to have higher overall anxiety of aging than men. The state of health is also an influencing factor. Women's state of mind is influenced by dissatisfaction with health and by conviction that health will worsen with age. When thinking about aging many women reported feeling upset by the thought that there could be situations in old age when outside help is needed for everyday activities. Due to this women's level of stress is considerably higher than men. The women are especially strongly influenced by negative emotions and fears due to the thoughts that old age may cause poverty and exclusion; emptiness or sadness; losing of friends and relatives. They fear that their health may worsen with age and that there could be need for outside help in an old age to cope with everyday activities etc.

\section{Age}

As compared to older and younger respondents, middle aged respondents were found to have greater anxiety about aging. The 2x3 ANOVA also revealed that in comparison to older and younger respondent's middle respondents scored higher on overall anxiety about aging $(\mathrm{M}=54.06,54.27$ and 52.74, $\mathrm{F}=1.181, \mathrm{P}>.01$ ). Thus the second hypothesis which stated that "in comparison to older respondents younger and middle aged respondents have greater anxiety about aging” is only partially supported by the findings of the present study. Middle aged respondents indeed exhibited greater aging anxiety. Anxiety about aging is an important construct in both the gerontological and development literature. Not only does anxiety about aging is likely to play a key role in adjustment to the aging process, but it is also hypothesized to be related to important psychological constructs such as well-being, life satisfaction and self efficacy in old age (Lasher and Watkins, 1998). Lasher and Faulkender (1993) found that younger adults and those with decreased frequency of contact with older adults reported significantly greater anxiety about how physical looks change with advancing age. Less contact with older adults and the negative stereotypes of old age which is widespread in our society makes younger respondent reluctant toward old age and older people. Negative attitudes, discrimination and myths all contribute to fears of aging. Lynch (2000) conducted a large sample study on fears of aging. Lynch found that aging anxiety was highest in young adulthood, held steady across middle age, then continued to decline further in the 50-64 and 65+ age groups. Another reason for a great deal of anxiety about aging in adult respondents is that western cultures continue to place value on youth and the characteristics associated with being young, while ascribing primarily negative characteristics such as illness, grouchiness, and physical unattractiveness to older adults (Crockett, e.t al 1987, Lutsky, 1980 \&McTavish 1971). Fear of growing old, may be universal and natural apprehension for many. Young centered culture is thus an important factor responsible for anxiety toward aging in younger adults (Traxler, 1980). 


\section{Gender and Age Related Differences in Anxiety about Aging}

Persons who are dependent on physical appearance and youth for their identity are likely to experience greater degree of anxiety toward old age and old people (Block, Davidson \& Grumbs, 1981). In addition anxiety and attitudes about aging are likely to influence life-style choices that may impact the quality of aging later on. The continuous and increasing effort and expense required to "maintain the appearance" and the accompanying backdrop of anxiety over the accumulating indicators (both actual and imagined) that the youthful attributes are eroding may cause a lot of stress.

Table 1, Anxiety about Aging - Fear of old people

\section{A. Means and SDs}

\begin{tabular}{|l|l|l|l|l|}
\hline Age & & Male & Female & Total \\
\hline \multirow{2}{*}{ 25-35 years } & M & 9.52 & 12.12 & 10.82 \\
\cline { 2 - 5 } & SD & 3.352 & 4.236 & 4.019 \\
\hline \multirow{2}{*}{$45-65$ years } & M & 10.24 & 14.34 & 12.29 \\
\cline { 2 - 5 } & SD & 3.537 & 5.985 & 5.307 \\
\hline \multirow{2}{*}{$65 \&$ above } & M & 6.94 & 7.54 & 7.24 \\
\cline { 2 - 5 } & SD & 3.803 & 1.515 & 2.896 \\
\hline \multirow{2}{*}{ Total } & $\mathrm{M}$ & 8.90 & 11.33 & 10.12 \\
\cline { 2 - 5 } & SD & 3.819 & 5.148 & 4.686 \\
\hline
\end{tabular}

\section{B. Summary ANOVA}

\begin{tabular}{|l|l|l|l|l|l|}
\hline $\begin{array}{l}\text { Source of } \\
\text { Variation }\end{array}$ & SS & DF & MS & F & P \\
\hline Age & 1349.32 & 2 & 674.663 & $42.939^{*}$ & 0.0000 \\
\hline Sex & 444.083 & 1 & 444.083 & $28.264^{*}$ & 0.0000 \\
\hline Age $x$ Sex & 154.167 & 2 & 77.083 & $4.906^{*}$ & 0.008 \\
\hline
\end{tabular}




\section{Gender and Age Related Differences in Anxiety about Aging}

\section{Graphical presentations of Means}

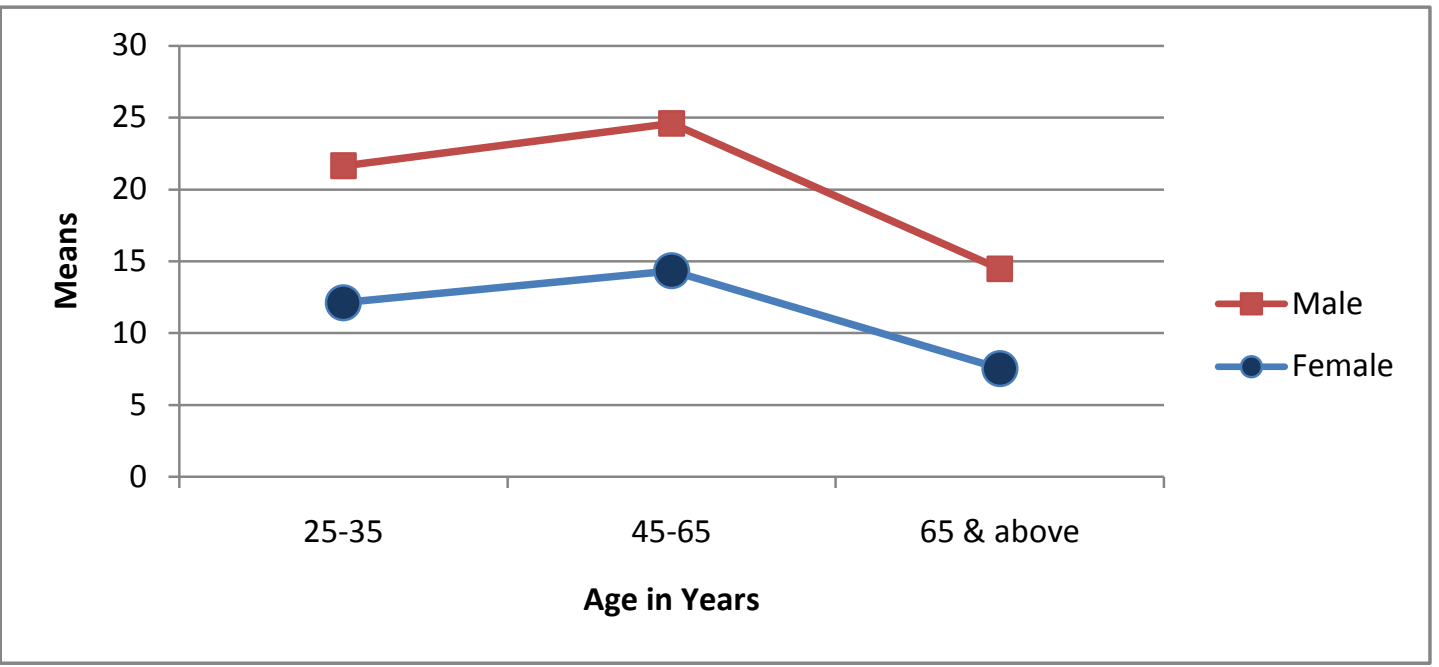

Table 2, Anxiety about Aging - Psychological Concern
A. Means and SDs

\begin{tabular}{|l|l|l|l|l|}
\hline Age & & Male & Female & Total \\
\hline \multirow{2}{*}{ 25-35 years } & $\mathrm{M}$ & 11.98 & 17.78 & 14.88 \\
\cline { 2 - 5 } & $\mathrm{SD}$ & 3.087 & 1.810 & 3.851 \\
\hline \multirow{2}{*}{$45-65$ years } & $\mathrm{M}$ & 12.68 & 13.20 & 12.94 \\
\cline { 2 - 5 } & $\mathrm{SD}$ & 3.571 & 1.262 & 2.677 \\
\hline \multirow{2}{*}{$65 \&$ above } & $\mathrm{M}$ & 14.52 & 13.94 & 14.23 \\
\cline { 2 - 5 } & $\mathrm{SD}$ & 1.555 & 1.812 & 1.705 \\
\hline \multirow{2}{*}{ Total } & $\mathrm{M}$ & 13.06 & 14.97 & 14.02 \\
\cline { 2 - 5 } & $\mathrm{SD}$ & 3.046 & 2.596 & 2.983 \\
\hline
\end{tabular}

\section{B. Summary ANOVA}

\begin{tabular}{|l|l|l|l|l|l|}
\hline $\begin{array}{l}\text { Source of } \\
\text { Variation }\end{array}$ & SS & DF & MS & F & P \\
\hline Age & 882.960 & 2 & 441.480 & $50.151^{*}$ & 0.0000 \\
\hline Sex & 1487.413 & 1 & 1487.413 & $168.967^{* *}$ & 0.0000 \\
\hline Age x Sex & 773.547 & 2 & 386.773 & $43.937^{* *}$ & 0.0000 \\
\hline
\end{tabular}


Gender and Age Related Differences in Anxiety about Aging

C. Graphical presentations of Means

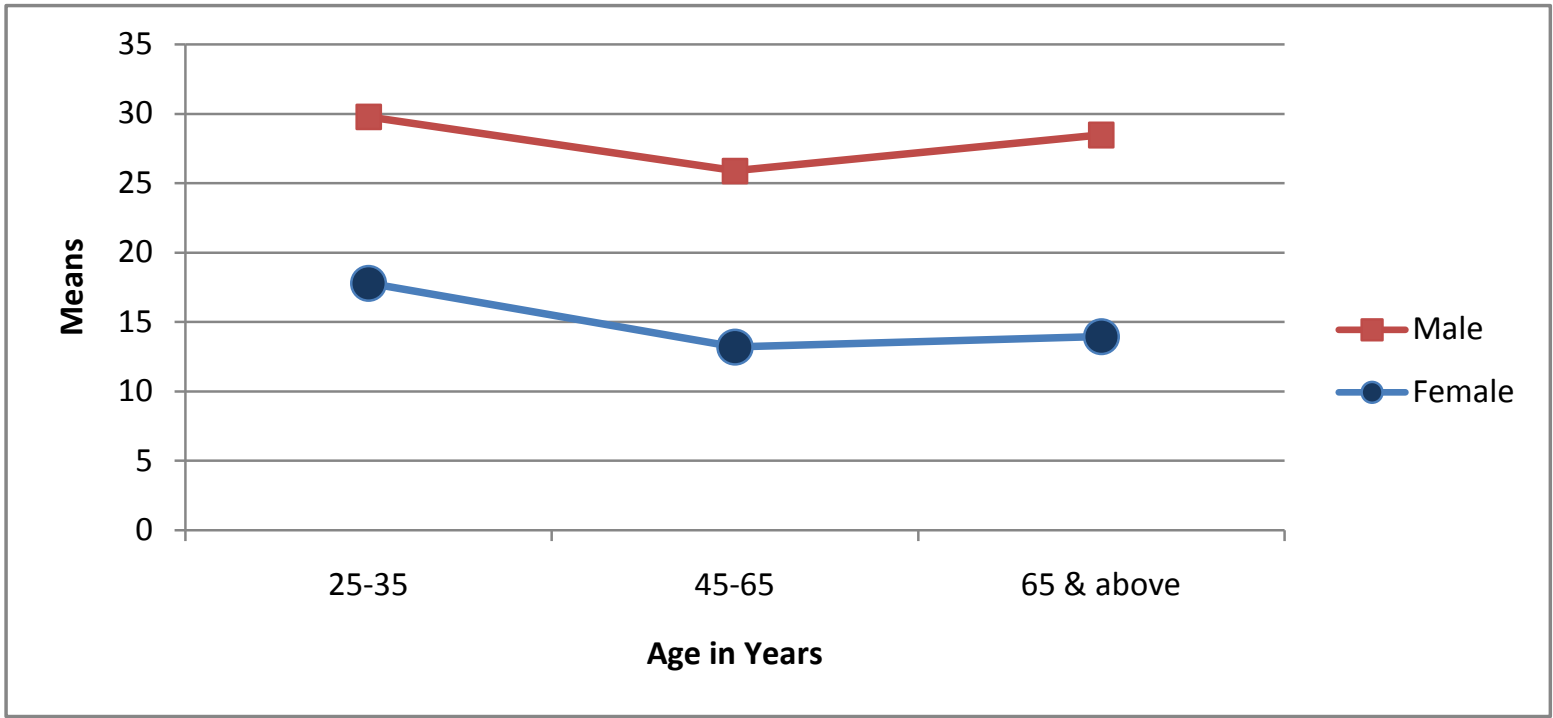

Table 3, Anxiety about Aging - Physical appearance
A. Means and SDs

\begin{tabular}{|l|l|l|l|l|}
\hline Age & & Male & Female & Total \\
\hline \multirow{2}{*}{ 25-35 years } & $\mathrm{M}$ & 11.22 & 11.94 & 11.58 \\
\cline { 2 - 5 } & $\mathrm{SD}$ & 3.986 & 2.614 & 3.373 \\
\hline \multirow{3}{*}{$45-65$ years } & $\mathrm{M}$ & 13.02 & 17.10 & 15.06 \\
\cline { 2 - 5 } & $\mathrm{SD}$ & 4.470 & 1.035 & 3.824 \\
\hline \multirow{3}{*}{$65 \&$ above } & $\mathrm{M}$ & 11.08 & 19.64 & 15.36 \\
\cline { 2 - 5 } & $\mathrm{SD}$ & 1.338 & 2.694 & 4.794 \\
\hline \multirow{2}{*}{ Total } & $\mathrm{M}$ & 11.77 & 16.23 & 14.00 \\
\cline { 2 - 5 } & $\mathrm{SD}$ & 3.629 & 3.914 & 4.378 \\
\hline
\end{tabular}

\section{B. Summary ANOVA}

\begin{tabular}{|l|l|l|l|l|l|}
\hline $\begin{array}{l}\text { Source of } \\
\text { Variation }\end{array}$ & SS & DF & MS & F & P \\
\hline Age & 882.960 & 2 & 441.480 & $50.151^{*}$ & 0.0000 \\
\hline Sex & 1487.413 & 1 & 1487.413 & $168.967^{* *}$ & 0.0000 \\
\hline Age x Sex & 773.547 & 2 & 386.773 & $43.937^{* *}$ & 0.0000 \\
\hline
\end{tabular}


Gender and Age Related Differences in Anxiety about Aging

C. Graphical presentations of Means

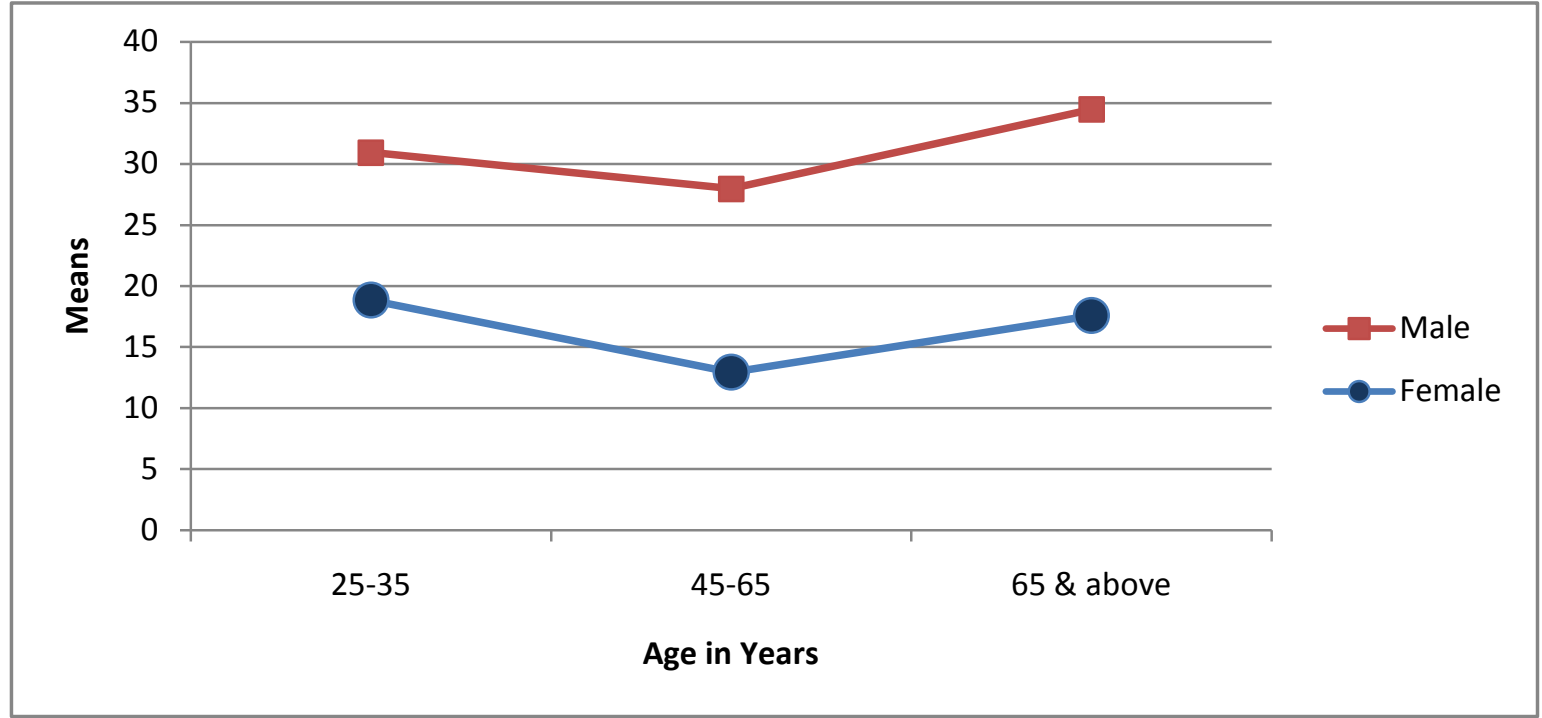

Table 4, Anxiety about Aging - Fear of loses
A. Means and SDs

\begin{tabular}{|l|l|l|l|l|}
\hline Age & & Male & Female & Total \\
\hline \multirow{2}{*}{ 25-35 years } & $\mathrm{M}$ & 12.08 & 18.84 & 15.46 \\
\cline { 2 - 5 } & SD & 5.565 & 1.346 & 5.269 \\
\hline \multirow{3}{*}{ 45-65 years } & $\mathrm{M}$ & 15.02 & 12.94 & 13.98 \\
\cline { 2 - 5 } & $\mathrm{SD}$ & 3.910 & 1.463 & 3.117 \\
\hline \multirow{2}{*}{ Total } & $\mathrm{M}$ & 16.88 & 17.58 & 17.23 \\
\cline { 2 - 5 } & $\mathrm{SD}$ & 4.719 & 2.287 & 3.706 \\
\hline & $\mathrm{M}$ & 14.66 & 16.45 & 15.56 \\
\cline { 2 - 5 } & $\mathrm{SD}$ & 5.145 & 3.082 & 4.328 \\
\hline
\end{tabular}

\section{B. Summary ANOVA}

\begin{tabular}{|l|l|l|l|l|l|}
\hline $\begin{array}{l}\text { Source of } \\
\text { Variation }\end{array}$ & SS & DF & MS & F & P \\
\hline Age & 529.527 & 2 & 264.763 & $20.443^{*}$ & 0.0000 \\
\hline Sex & 241.203 & 1 & 241.203 & $18.624^{*}$ & 0.0000 \\
\hline Age $x$ Sex & 1021.647 & 2 & 510.823 & $39.442^{* *}$ & 0.0000 \\
\hline
\end{tabular}


Gender and Age Related Differences in Anxiety about Aging

C. Graphical presentations of Means

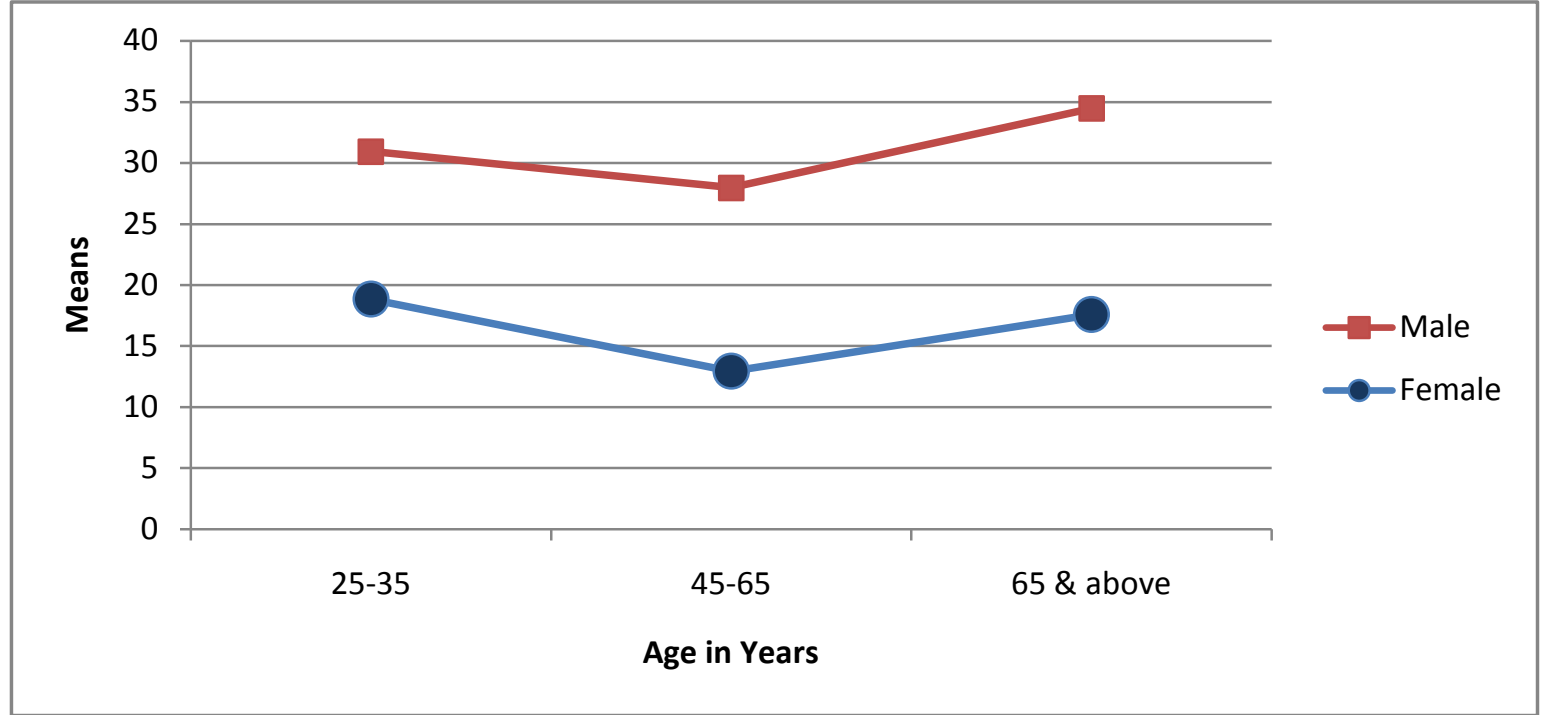

Table 5 Anxiety about Aging (Total)
A. Means and SDs

\begin{tabular}{|l|l|l|l|l|}
\hline Age & & Male & Female & Total \\
\hline \multirow{2}{*}{ 25-35 years } & M & 44.80 & 60.68 & 52.74 \\
\cline { 2 - 5 } & SD & 10.057 & 6.535 & 11.614 \\
\hline \multirow{3}{*}{ 45-65 years } & M & 50.96 & 57.58 & 54.27 \\
\cline { 2 - 5 } & SD & 9.744 & 7.051 & 9.092 \\
\hline \multirow{2}{*}{ Total $\&$ above } & $\mathrm{M}$ & 49.42 & 58.70 & 54.06 \\
\cline { 2 - 5 } & SD & 6.716 & 3.981 & 7.205 \\
\hline & $\mathrm{M}$ & 48.39 & 58.99 & 53.69 \\
\cline { 2 - 5 } & SD & 9.285 & 6.104 & 9.470 \\
\hline
\end{tabular}

B. Summary ANOVA

\begin{tabular}{|l|l|l|l|l|l|}
\hline $\begin{array}{l}\text { Source of } \\
\text { Variation }\end{array}$ & SS & DF & MS & F & P \\
\hline Age & 137.580 & 2 & 68.790 & 1.181 & 0.001 \\
\hline Sex & 8416.403 & 1 & 8416.403 & $144.503^{* *}$ & 0.0000 \\
\hline Age $x$ Sex & 1136.527 & 2 & 568.263 & $9.757^{* *}$ & 0.0000 \\
\hline
\end{tabular}




\section{Graphical presentations of Means}

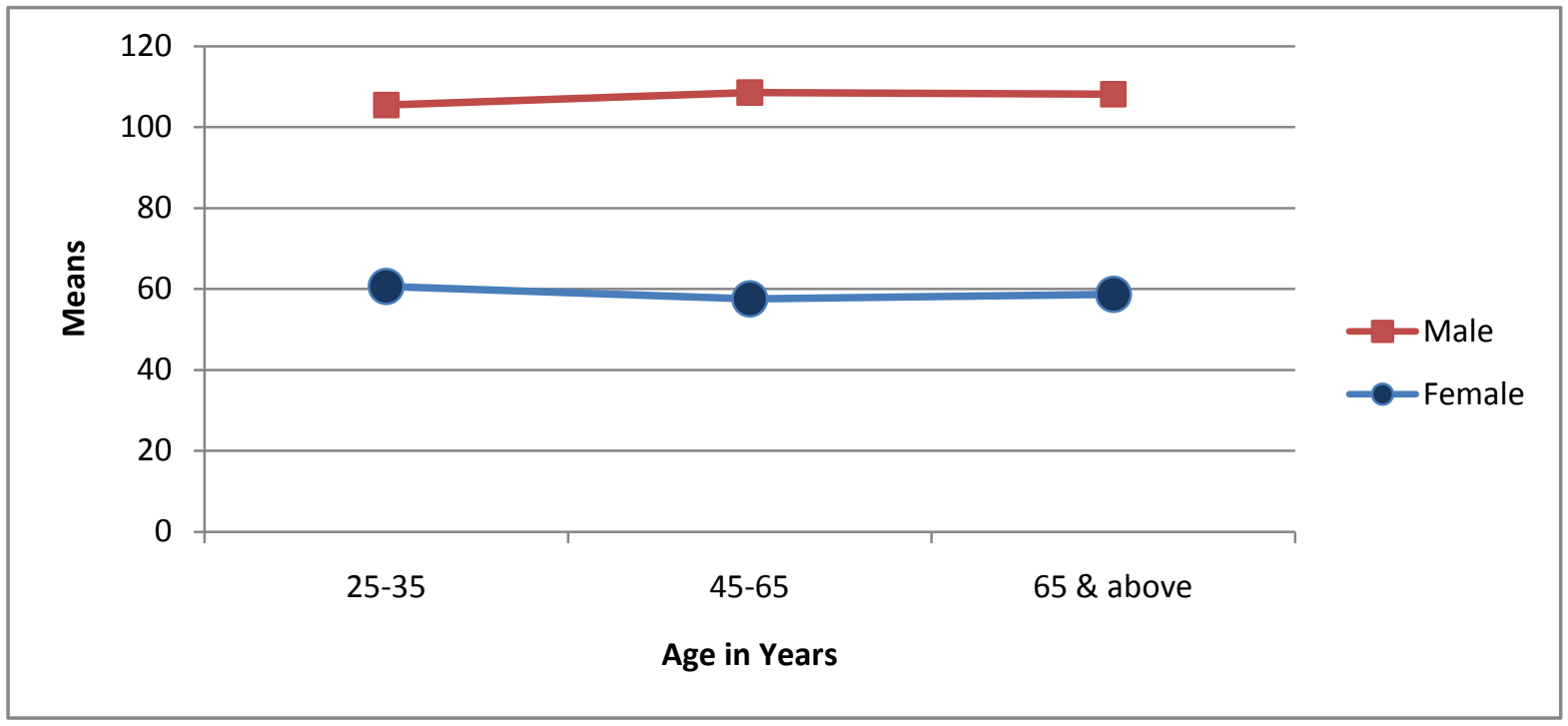

\section{IMPLICATIONS}

This study has some theoretical and practical implications. Theoretically, the results obtained could be used to improve existing theories of anxiety about aging (Fortner \& Neimeyer, 1999) or could be added to anxiety models. Practically, anxiety about aging studies are extremely useful in improving the quality of older people and health care services for those who have high levels of anxiety about aging. By pointing out the variables involved in increasing or decreasing anxiety, professionals can work towards reducing or promoting them respectively (Fortner \& Neimeyer, 1999). An example would be to have support groups for these individuals to express their fears and concerns as well as find healthy and effective ways to deal with their anxiety.

\section{CONCLUSION}

In conclusion, two hypotheses of the study were supported. The study found that anxiety about aging are higher for females as compared to males and middle aged respondent's have high level of anxiety about aging as compared to younger and older respondents anxiety .Further refinement of anxiety about aging measurements, research methods as well as more crosscultural studies could shed light on this amazingly complex yet interesting topic of anxiety about aging.

Researchers speculate that this may be because women are very worried about their physical appearance. Society stresses the appeal of looking young, especially for women. Women also have health concerns, but physical appearance is a consistently more important fear associated with aging in women than it is in men. 


\section{Gender and Age Related Differences in Anxiety about Aging}

Older adults may use various other options for maintaining a positive self-image such as leisure, an easy paced life, recreation, social-community involvement/service, religious affiliation and activities, etc.

Perhaps people usually are more accepting of what befalls on them than some far away, anticipated event.

\section{Acknowledgments}

The author appreciates all those who participated in the study and helped to facilitate the research process.

\section{Conflict of Interests}

The author declared no conflict of interests.

\section{REFERENCES}

Abramson, A. \& Silverstein, M. (2006). Images of aging in America 2004; A summary of selected finding.

Retrieved September 20, 2006, from http://assets.aarp.org/rgcenter/generaly/images_ aging.pdf

Block, N.R. Davidson, J.L. \& Grambs, J.D. (1981). Women Over Forty: Visions \& Realities. New York: Springer.

Byrne, D., \& Kelley, K. (1981). An introduction to personality (3rd ed.). Englewood Cliffs. NJ: Prentice-HalL

Crockett, W.H. \& Hummert, M.L. (1987). Perceptions of aging and the elderly. In K.W. Schaie (Ed.), Annual Review of Gerontology \& Geriatrics (Vol. 7, pp. 217-292). New York: Springer.

Cummings, S.M. KroPF, N.P. \& DeWeaver, K.L. (2000). Knowledge of and attitudes toward aging among non-elders: Gender and race differences. Journal of Women \& Aging, 12, 77-91.

Dhar, Aarti, (2012) Concerns over an Aging India. The Hindu, Oct. 7

Featherstone, M. and Hepworth, M. (2000). Images of aging. In J. Bond, P. Coleman and S. Peace (eds.). Aging in Society: An Introduction to Social Gerontology. London: Sage.

Goffman, E. (1959).The presentation of self in everyday life. New York: Doubleday

Harris, M.B. (1994). Growing old Gracefully: Age Concealment and gender. Journal of Gerontology, 49, P149-P158.

Hooyman. N. R. \&. Kiyak- H A (1993). Social gerontology f3rd ed. A Boston, MA: AUyn \& Bacon.

Hummert, M.A., Garstka, T.A., Shaner, J.L. \& Strahm, S. (1994). Stereotypes of the elderly held by young, middle-aged \& elderly adults. Journal of Gerontology, 49(5), 240-249.

Kafer, R. A., Rakowski, W., Lachman, M., \& Hickey, T. (1980). Aging opinion survey: A report on instrument development. International Journal of Aging and Human Development,11, 319-333.

Kalish, R. (1985). Death, grief and caring relationships (2nd ed.). Monterey, CA: Brooks/Cole 


\section{Gender and Age Related Differences in Anxiety about Aging}

Lasher, K.P. \& Faulkender, P.J. (1993).Measurement of aging anxiety: Development of anxiety about aging scale. International Journal of Aging and Human Development, 37(4), 247259.

Lutsky, N. (1980). Attitudes toward old age and elderly Persons. In C. Eisdorfer (Ed.), Annual review of gerontology and geriatrics (Vol.1, pp. 287-336). New York: Springer.

Lynch, S.M. (2000). Measurement and prediction of aging anxiety. Research on Aging, 22(5), 553-558

McTavish, D.G. (1971). Perceptions of old people: A review of research methodologies and findings. The Gerontologist, 11, 90-101.

Montepare, J.M. \& Lachman, M.E. (1989). "You're only as old as you feel": Self-Perceptions of age, fears of aging and life satisfaction from adolescence to old age. Psychology of Aging, 4, Fitzgerald, J.M. \& Hyland, D.T. (1980). Perceptions of development. Research on Aging, 2, 351-366(C). Naus, P.J. (1973). Some correlates of attitudes towards old people. International Journal of Aging Human Development, 4, 229-243.(E)

Nelson, Dean (2013) India facing elderly population 'time bomb'. The Telegraph, Wednesday, June 26

Nevgarten, B.L., Moore, J.W. \& Lowe, J.C. (1965). Age norms, age constraints and adult socialization. American Journal of Sociology, 70,710-717.

Pinquart, M. \& Sorensen, S. (2001). Gender differences in Self-concept and Psychological well being in old age: A met analysis. Journal of Gerontology,56B, P123-P195.

Scommegna, Paola (2012) India's Aging Population. Population Reference Bureu.w.w.w.prb.org. /Reports/2012/India-older-population.aspx

Seccombe, K. \& Ishii-Kuntuz, M. (1991). Perceptions of problems associated with aging: Comparisons among Poor older age cohorts. The Gerontologist, 31, 527-533.

Sontag, S. (1972). The double Standard of aging. Saturday Review, 55, 29-38.

Traxler, A.J. (1980). Let's etgerontologized. Developing a Denstivity to aging, the multipurpose Senior Center Concept. A training manual for practitioners working with the aging. Springfield. IL. Illinois Department of Aging.

Watkins, R. E., Coates, R., \& Ferroni, P. (1998). Measurement of aging anxiety in an elderly Australian population. International Journal of Aging and Human Development, 46, 319332.

Zeplin, H., Sills, R.A. \& Health, M.W. (1986-87). Is age becoming irrelevant ?An exploratory Study of perceived age norms. International Journal of Aging and Human Development, 24, 241-256.

How to cite this article: R Saxena, A Shukla (2016), Gender and Age Related Differences in Anxiety about Aging, International Journal of Indian Psychology, Volume 3, Issue 4, No. 63, ISSN 2348-5396 (e), ISSN: 2349-3429 (p), DIP: 18.01.097/20160304, ISBN: 978-1-365-325182 